\title{
CRISIS CAPITALISTA Y ALTERNATIVAS CONTRAHEGEMÓNICAS
}

\author{
Napoleon Saltos Galarza \\ Universidade Central do Equador (UCE)
}

\section{CRISIS CAPITALISTA Y ALTERNATIVAS CONTRA-HEGEMÓNICAS}

Resumen: El texto trata de la crisis capitalista y de las alternativas contra-hegemónicas construidas en la contemporaneidad. Parte de la perspectiva de que crisis son momentos de reorganización del capital: destruyen para reconstruir. Deben ser encaradas como paradojas, con poderes y posibilidades contrapuestos. Son crisis superpuestas: bancaria, financiera, económica, de hegemonía, bélica, ecológica que apuntan hacia una crisis estructural y civilizatoria. Discute, además, el actual mapa político de América Latina que está enmarcado en tres puntos-clave: signos de fronteras de los gobiernos progresistas, surgimiento de un nuevo eje alineado en torno a la Alianza del Pacífico y la emergencia de nuevos movimientos antisistémicos.

Palabras claves: Capital, crisis, contra-hegemonía, movimientos sociales.

\section{CAPITALIST CRISES AND COUNTERHEGEMONIC ALTERNATIVES}

Abstract: The text deals with the capitalist crises and the counterhegemonic alternatives built in contemporaneity. Starts on the perspective that crises are moments of capital reorder: destroy to construct. Should be faced as paradoxes, with powers and opposed possibilities. They are superimposed crises: banking, financial, economic, hegemonic, military, ecological which point in the way of a structural crisis and civilizing. It still discusses the current politic map of Latin America which is delimited in three key-spots: border signs of progressist governs, arisal of a new axis aligned around the Pacific Alliance and the emergency of new social antisistemic movements.

Keywords: Capital, crises,counterhegemonic, social movements. 


\section{INTRODUCCION}

Sin sueños no puede haber cambio, no se puede "vivir buenamente", sobre todo en tiempos de crisis. La hegemonía implica alguna forma de ilusión, de esperanza colectiva.

Hace poco decía un dirigente indígena:

\begin{abstract}
Hemos vivido un tiempo de esperanza: la llegada de los gobiernos "progresistas" abrió expectativas sobre todo en los de abajo. Parece que este período empieza a cerrarse. Cuando se pierde la confianza se rompe el encantamiento.
\end{abstract}

El tiempo histórico de los gobiernos progresistas empieza a agotarse. La esperanza de los cambios retorna abajo. La labor de los sabios es expresar la sabiduría de los simples, decía San Buenaventura. Más responsabilidad que el que más tiene, la tiene el que más sabe. El intelectual orgánico alternativo instaura la visión del mundo a partir de las visiones, los sueños, los intereses, los sentidos comunes de los simples.

\section{TIEMPO DE TRANSICION}

Vivimos un tiempo marcado por dos procesos: la crisis y decadencia del capital y la emergencia de signos anti-sistémicos, de la transición hacia formas post-capitalistas.

Se trata de varias crisis superpuestas: bancaria, financiera, económica, de hegemonía, bélica, ecológica; por ello, con signos de una crisis estructural y civilizatoria.

La crisis debe ser vista bajo la forma de paradojas, con poderes, posibilidades, potencialidades contrapuestas.

La paradoja de la abundancia y la escasez: un tiempo en que la humanidad está en capacidad de pasar a la abundancia y cambiar el objeto de la economía; pero esa potencialidad se convierte en su contrario por la apropiación privada monopolista que llega a las formas más extremas y produce nuevas formas de expropiación, pobreza y exclusión. Allí se expresa la contradicción básica en la que se mueve la posibilidad del cambio de un sistema: las fuerzas productivas que se universalizan y las relaciones de producción que se privatizan; una expropiación de las potencialidades de la humanidad por el poder del capital.

La paradoja de la democracia y el fascismo social (DE SOUZA SANTOS, 2004), de la paz y la guerra. La disputa del monopolio de la violencia legitimada vuelve al centro ante la crisis de la hegemonía norteamericana. Se abre la puerta a un nuevo ciclo hegemónico o la posibilidad del paso a un nuevo mundo fundado en la paz general y el bien común de la humanidad.
La paradoja ecológica. La humanidad retorna a la definición de su relación con la naturaleza, al punto de partida de la constitución de la modernidad:

[...] la condición primera de posibilidad de esa revolución civilizatoria que conocemos como modernización se encuentra en una alteración profunda de la relación técnica del ser humano con la naturaleza. [...] La civilización moderna aparece cuando aparece la "neotécnica", es decir, cuando la vida civilizada aprovecha el incremento exponencial de la productividad del trabajo humano que esa neotécnica trae consigo. Lo que va a determinar la consistencia de esta modernidad es precisamente el modo en que lleve a cabo este aprovechamiento, la manera que tenga de integrarlo en su civilización. $Y$ es que la neotécnica no incita solamente a un salto cuantitativo en el rendimiento de las fuerzas productivas; incita igualmente a un salto cualitativo en la definición misma de lo que es ese rendimiento, de lo que es el trabajar y el producir. La neotécnica abre para el ser humano la posibilidad de replantear desde la base, radicalmente, la relación que ha mantenido con la naturaleza; le pone en condiciones de abandonar la relación de conquista y dominio que él ha buscado tradicionalmente imponer sobre ella, y de establecer con ella una relación nueva, de colaboración entre iguales, en la que ninguno de los dos se somete al otro ni se impone sobre él. Dos proyectos de modernidad se esbozan a partir de este doble nivel de transformación civilizatoria desatado por la revolución neotécnica; dos proyectos que se definen según el modo de aprovechar esa transformación que tiene cada uno de ellos. (ECHEVERRIA, 2008).

La neotécnica de la tercera revolución científico-técnica nos coloca nuevamente ante la posibilidad de redefinir nuestra relación la naturaleza: en la fase actual, de capitalismo tardío y de transición vivimos los dos modelos en su forma extrema. El capitalismo tardío lleva al modelo de modernidad capitalista, la subordinación del valor de uso por el valor de cambio, el predominio del modelo de la cantidad sobre la calidad, a su forma extrema, con riesgo para la subsistencia de la naturaleza y de la humanidad.

El capital tiene alta flexibilidad. Las crisis son un momento de reordenamiento del capital: destruye para reconstituirse. la tendencia

En el capitalismo se presenta periódicamente 
[... a producir crisis de sobreacumulación[...] (que) se expresan como excedentes de capital y de fuerza de trabajo que coexisten sin que parezca haber manera de que puedan combinarse de forma rentable a efectos de llevar a cabo tareas socialmente útiles, [...] la incapacidad de acumular a través de la reproducción ampliada sobre una base sustentable." (HARVEY, 2004).

Las salidas cíclicas pasan por devaluaciones sistémicas (e incluso destrucción) de capital y fuerza de trabajo y por ajustes espacio-temporales, desplazamiento a nuevos ejes de acumulación que implican también desplazamientos espaciotemporales, desplazamientos geoeconómicos. Se produce un viraje a un imperialismo abierto respaldado por la fuerza militar norteamericana. Esta política

[...] ha sido acompañada por crecientes intentos de acumular mediante la desposesión. Alli se asienta el carácter del "nuevo imperialismo". (HARVEY, 2004).

Después de la crisis hipotecaria del 2008, el capital financiero global se mueve en cuatro direcciones combinadas: (i) produce devaluaciones sistémicas de capital ficticio, con el traslado de los costos sobre todo a la periferia europea; (ii) proyecta a un imperialismo abierto respaldado por la fuerza militar norteamericana con guerras sobre todo en Medio Oriente por el control de los recursos estratégicos y la contención de la expansión del eje Este-Oeste, encabezado por los BRICs. Hoy predomina la destrucción (Irak, Libia, Siria), sin capacidad de reconstitución; (iii) se desplaza a nuevos terrenos, al capital rentista, ya no sólo la renta tradicional de la tierra, la explotación de los recursos naturales, sino ahora en combinación con la renta del conocimiento; y (iv) refuerza las formas de acumulación por desposesión, en torno a energía/hidrocarburos, construcción/infraestructura, agricultura transgénica/ agrocombustibles.

Al mismo tiempo, vuelve la posibilidad del otro modelo de modernidad, basado en el respeto y la armonía con la naturaleza, la reintegración de la humanidad como parte de la naturaleza, del "Madre-Tierra". Y en ese camino las modernidades inconclusas o subalternas, los caminos del ethos barroco, ofrecen nuevamente su potencialidad.

Las movilizaciones sociales atraviesan todos los Continentes. En América Latina empieza una nueva fase, todavía a la defensiva, de autonomización ante los gobiernos progresistas, con signos de tendencias antisistémicas.

El desenlace de la crisis es siempre político. Las disputas hegemónicas se concentran en el sentido: el poder se presenta como bio-poder, como el control de la vida de la gente. Estamos ante nuevas formas de colonialismo del conocimiento basado en una visión neopositivista: la seducción tecnológica.

\section{UNA NUEVA FASE EN NUESTRA AMÉRICA}

Si hubiéramos hablado hace dos o tres años, el centro de la reflexión hubiera sido el proceso de los gobiernos progresistas, sus políticas de cambio. El proceso que se abre con el triunfo de Hugo Chávez en 1998 y se expande con el acceso por la vía electoral de gobiernos progresistas en todo el Continente.

Ahora el mapa político de América Latina ha cambiado en tres puntos clave: signos de fronteras de los gobiernos progresistas, surgimiento de un nuevo eje alineado en torno a la Alianza del Pacífico y la emergencia de nuevos movimientos sociales antisistémicos. Empieza a modificarse la correlación de fuerzas.

La muerte de Chávez se presenta como el signo de las fronteras de los gobiernos "progresistas" en Venezuela y en el Continente.

Con la emergencia de las nuevas movilizaciones sociales en junio, asistimos al fin de las revoluciones pasivas, no sólo en Brasil:

[...] revolución pasiva: un proceso de modernización impulsado desde arriba que recoge sólo parcialmente las demandas de los de abajo y con ello logra garantizar su pasividad, su silencio más que su complicidad [...] El agotamiento tiene que ver [...] ]sobre todo con la pérdida de impulsos progresistas y el aumento significativo de rasgos conservadores en la coalición social y política encabezada por Lula y que sostiene el gobierno de Dilma. [...] La movilización levanta el velo y muestra la realidad contradictoria y las miserias ocultas detrás del mito del milagro brasileño, que ya había funcionado décadas atrás y que volvió a aparecer en los últimos años. [...] La pasividad sobre la cual se erigía la hegemonía lulista se disuelve en las calles. (MODONESI, 2013).

Esta variación se asienta en una modificación de la base económica. El desplazamiento del capital financiero hacia el eje rentista generó una oleada de subida general de los precios de las commodities. Esta tendencia se inicia en torno al 2003-2004.

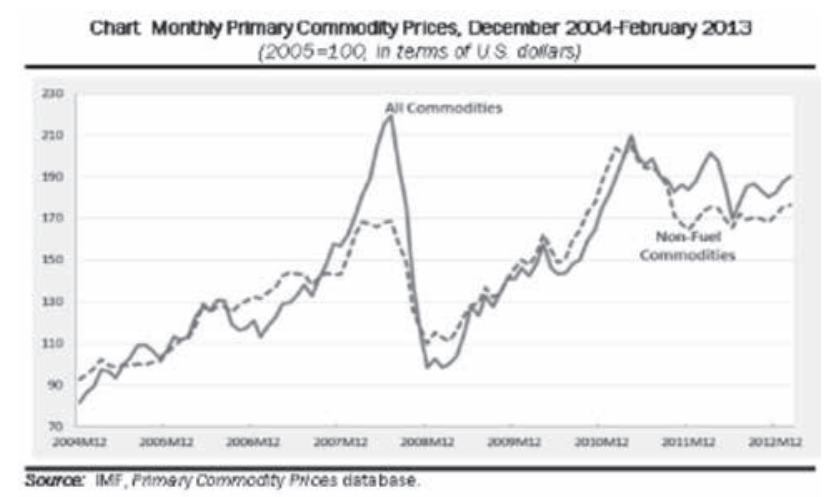


The boom that had started in 2003 continued until summer 2008 with the index for all primary commodities rising by more than threefold (Chart 6). This was followed by a steep downturn in the second half of 2008 , which took the index back to the level of 2004. But like capital flows and remittances, commodity prices also recovered strongly from the beginning of 2009, rising until spring 2011 when they levelled off and started to fall, manifesting increased short-term instability. In the early months of 2013 , the index for all commodities was 15 per cent below the peak reached in summer 2008. (AKYUZ, 2013).

Aquí inciden diversos factores geoeconómicopolíticos. El desplazamiento del capital financiero hacia el eje rentista de acumulación se desarrolla en medio de una modificación del ordenamiento mundial: mientras las crisis se concentran en el eje Norte-Sur, encabezado por las potencias tradicionales - Estados Unidos, Europa y Japón -, emerge un nuevo eje de acumulación Este-Oeste, hay un despunte de los BRICs, las potencias emergentes, encabezadas por China.

Con ello, se amplía el espacio de vinculación internacional para los países periféricos; se aflojan las clavijas de dependencia directa del imperialismo norteamericano, se abren oportunidades de vinculación económica hacia el eje Este-Oeste y se desarrollan iniciativas limitadas de soberanía e integración continentales: UNASUR, Banco del Sur, CELAC, ALBA.

América Latina se enanca en estas tendencias, lo que abre un período de crecimiento "anticíclico" de la Región en torno al 5\% anual, mientras los países del centro soportan situaciones de crisis. El resultado es un período de abundancia, sobre todo en manos del Estado, a partir de la cual se impulsan políticas de redistribución y asistencia social que contribuyen a una amplio respaldo social a los regímenes: 1 de cada 4 latinoamericanos cuenta con alguna especie de bono social.

Este enancamiento implica una paradoja, sobre todo para los gobiernos progresista". Mientras en las nuevas Constituciones garantistas se declara los derechos de la naturaleza, [...] atravesados por las nociones del Buen Vivir/Vivir Bien (suma qamaña, sumak kawsay), sin embargo

[...] en el conjunto de los países de Sudamérica, en la última década se acentuado la dependencia primarioexportadora. En cada uno de estos países (Venezuela, Ecuador y Bolivia) es muy elevada la participación de los productos primarios como proporción del valor total de las exportaciones. Se ha mantenido o incrementado en los años de los gobiernos de cambio. (LANDER, 2013).
Una tendencia similar se observa en el Cono Sur. Uno de los signos es

el enclave sojero en Sudamérica: En 2012 Argentina, Bolivia, Brasil, Paraguay y Uruguay sembraron 50 millones de hectáreas con soja transgénica, es decir 500 mil Km2 de un único monocultivo. Una superficie 200 mil Km2 más grande que Italia o 150 mil Km2 mayor que la extensión de Alemania. Un "desierto verde" del tamaño aproximado del estado español. (BERTERRETCHE, 2013).

Esta base material define el carácter de los gobiernos progresistas como regímenes de cambio de ciclo, regímenes postneoliberales, pero sin poder enfrentar el cambio del patrón capitalista de acumulación: modelos de modernización capitalista con fortalecimiento del Estado y procesos de redistribución y asistencia social.

Desde allí, los regímenes progresistas se presentan como variaciones de formas bonapartistas.

El gobierno de Lula se presenta como

una variante de semibonapartismo en el cual la cooptación y el control del llamado sindicalismo combativo y, en particular, de la cúpula sindical es decisivo [...] Lula, al comienzo del segundo mandato, hizo un cambio político importante, trasladando su base social de sustentación hacia las camadas más pauperizadas, que viven al margen de la organización de clase: ... amplió el Bolsa-Familia, con una política focalizada y asistencialista, pero de gran amplitud, dado que alcanza aproximadamente a 13 millones de familias pobres (cerca de 50 millones de personas con bajos ingresos salariales), que así reciben en promedio el equivalente a 50 dólares mensuales[...] De ese modo, articuló las dos puntas: remuneró a las diversas fracciones burguesas $y$, en el extremo opuesto de la pirámide social, donde están los sectores más desorganizados y empobrecidos de la población, brindó una política asistencialista que no afecta ni siquiera mínimamente ninguno de los pilares estructurales de la tragedia brasilera. (ANTUNES, 2011)

Aunque más bien hay una superposición de formas de hegemonía: una especie de barroquismo político o de formas abigarradas de funcionamiento del Estado y el poder (ZAVALETA, 2006)

En la hegemonía 1, referida al acuerdo arriba y a la constitución del bloque histórico dirigente y la visión hegemónica del mundo y de la vida, se presentan formas bonapartistas ampliadas, con arbitrajes no sólo internos sino también transnacionales y la expresión del interés general 
del capital en proyectos reflejos de modernización, más allá de las contradicciones internas y los alineamientos internacionales.

En la hegemonía 2, referida al consenso activo de las clases subalternas se reproducen estructuras populistas y diversas formas de transformismo que se expresan en un apoyo pasivo de las masas a los gobiernos progresistas y en el paso de actores/movimientos sociales autónomos a base electoral de maniobra. La paradoja en este terreno es que en el período de los gobiernos progresistas se produce un creciente debilitamiento de las organizaciones sociales que sustentaron el período de resistencia antineoliberal y la construcción de imaginarios constituyentes.

En la hegemonía 3, referida a práctica contrahegemónicas de las clases y fuerzas subalternas, una tendencia fuerte ha sido la respuesta autoritaria y represiva, con hechos de criminalización de las luchas sociales, enmarcadas en visiones de códigos penales del enemigo. Estas formas no se presentan como estructuras dadas, sino como procesos de ajuste progresivo, con la tendencia a un distanciamiento cada vez más marcado entre los gobiernos progresistas y los movimientos sociales organizados.

La oleada de precios altos de la commodities empieza a modificarse en el 2013, y asistimos a una

[...]"gran incertidumbre sobre si se ha terminado el "superciclo" alcista de los precios de commodities, (materias primas) que desde el 2003 y 2004 subieron fuertemente lo que favoreció a las exportaciones básicas de minerales, alimentos y energía. (CARCAMO, 2013).

La tendencia a la baja en la demanda y el precio de los "commodities" se ha transformado en una preocupación constante para las economías de la región. A esto hay que agregar un escenario externo determinado por la desaceleración del crecimiento de China, principal consumidor de los recursos naturales de la región, y la recesión en la zona euro. (COMISSIÓN ECONÓMICA PARA AMÉRICA LATINA, 2013).

En particular hay una tendencia a la baja en el precio internacional del petróleo, por la incidencia de diversos factores geoeconómicopolíticos: las negociaciones de Estados Unidos con Irán abren la perspectiva de la afluencia de millones de barriles al mercado hidrocarburífero; la introducción masiva del fracking y el cracking en la extracción de petróleo y gas en Estado Unidos y Canadá, a pesar de los altos costos ambientales, apunta a una modificación profunda de la tendencia mundial, pues estos dos países se convertirían en productores con capacidad de abastecimiento interno y de exportación.

Hacia finales del 2013 hay una baja del precio internacional, lo que empieza a afectar a los países exportadores de petróleo, como en el caso de Venezuela y Ecuador. Si bien no se trata de una caída brusca, hay una tendencia a la baja: en Venezuela, [...] el precio de venta promedio en lo que va de año se sitúa en 99,87, por debajo de los 103,42 dólares del año pasado. ${ }^{1}$

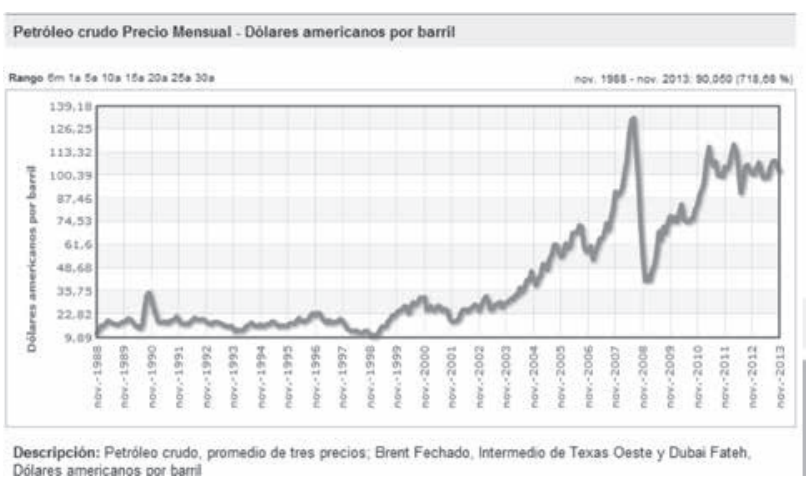

Fuente: http://www.indexmundi.com/es/precios-demercado/?mercancia $=$ petroleo-crudo\&meses $=300$

La incertidumbre está marcada por el paso del período de abundancia a gérmenes de un período de escasez, lo que puede afectar a la base del modelo de adhesión y control populista de la masa social y a la capacidad del Estado para organizar las contradicciones arriba.

\section{EL TIEMPO DE LOS MOVIMIENTOS SOCIALES}

La fase de ascenso de los gobiernos progresistas en nuestra América parte de los imaginarios de cambio originados en las luchas de los movimientos sociales.

En los setenta hasta mediados de los ochenta se presenta un bloque social liderado por el movimiento sindical. El tiempo de las luchas contra las dictaduras y por la democracia. A mediados de los ochenta se inicia un reflujo del movimiento sindical y surgen nuevos movimientos sociales, en particular, el movimiento indígena. A fines de los 90 entramos en una tercera fase con el paso al acceso de gobiernos progresistas por la vía electoral (SALTOS, 2013).

El imaginario constituyente abierto en la década de los 90 se instaura en el cimiento de los procesos constituyentes del nuevo siglo. Pero allí se produce una transformación de los sujetos: el clásico proceso de los jacobinos a los girondinos y a la restauración de Bonaparte toma su propia forma en América Latina (SALTOS, 2013a).

El poder constituyente se presenta como el concepto de una crisis. El poder constituyente emerge más allá del derecho y ordena el sistema de derecho. Se produce la tensión entre un poder absoluto que busca ser cerrado desde el orden constituido. 
El tiempo que es propio del poder constituyente, un tiempo dotado de una formidable capacidad de aceleración, tiempo del alumbramiento y de la generalización de la singularidad, deberá ser cerrado, detenido, reducido en las categorías jurídicas, restringido en la rutina administrativa," debe ser normado, "su expansividad no se revelará más que como norma interpretativa, como control de constitucionalidad, como actividad de revisión constitucional [...] el nexo que históricamente liga el poder constituyente al derecho de resistencia (y que de entrada define, por así decir, la figura activa) es cancelado; lo que queda es sometido a todas las posibles sevicias (NEGRI, 1993).

Una vez quebrado el poder constituyente se pasa a un proceso ordenado.

El paradigma es seccionado: al poder constituyente originario o comitente se opone (sigue, se distingue, se contrapone) el poder constituyente en sentido propio, asamblear; en fin, a los dos primeros, se opone el poder constituido. De este modo, el poder constituyente es absorbido en la máquina de la representación. El carácter ilimitado de la expresión constituyente es limitado en su génesis, puesto que es sometido a las reglas y a la extensión relativa del sufragio; en su funcionamiento, puesto que es sometido a las reglas asamblearias; en su periodo de vigencia (que se detiene funcionalmente delimitado, casi en la forma de la "dictadura" clásica, más que con referencia a la idea y a la práctica de la democracia) en fin y en suma, la idea de poder constituyente es jurídicamente preformada allí donde se pretendía que ella formase el derecho, es absorbida en la idea de representación política allí donde se quería que ella legitimase este concepto. De este modo, el poder constituyente, en cuanto elemento conectado con la representación (e incapaz de expresarse si no es a través de la representación) viene insertado en el gran diseño de la división social del trabajo. (NEGRI, 1993).

La tensión principal que atraviesa la relación entre la lucha de los movimientos sociales y el ordenamiento de los gobiernos posliberales es la disputa de vías diferentes de modernidad: una modernidad funcional al nuevo orden mundial en crisis, o una modernidad con reformas que se proyecta a diversas formas de revolución postcapitalista.

Vaciado el poder constituyente, el tiempo constitucional y el tiempo constituido se presentan como condensación del tiempo pasado, la legitimidad de un triunfo electoral que es ejercido hasta el próximo ejercicio, ya no un presente abierto al futuro de ruptura; y se ve la amenaza extrema en la emergencia de poderes subversivos.

En particular está en juego la relación entre soberanía popular como fundamento del poder y el orden constituido. Desde la visión del poder constituido la soberanía es evocada como una fuerza trascendente y abstracta, como principio de legitimación a posteriori, una especie de teleología en futuro-pasado, y no como la fuerza que constituye y permanece abierta en una relación que atraviesa el tiempo.

El poder constituyente es esta fuerza que se proyecta, desde la ausencia de finalidad, como tensión omnipotente y cada vez más expansiva. Ausencia de presupuestos y plenitud de la potencia: éste es un muy positivo concepto de libertad [...]. Aquí hay una sola condición correcta -y paradójica- para la definición de un concepto de soberanía ligado al de poder constituyente, y es que exista como praxis de un acto constitutivo, renovado en la libertad, organizado en la continuidad de una praxis libre. (NEGRI, 1993).

El poder constituyente se expresa como potencia abierta. De allí emerge una conclusión:

[...]quela potencia, institucionalizándose, no pueda más que negarse.

[...] Porque en el acto constitutivo no está nunca presente una dimensión vertical y totalitaria, sino que están presentes y activos la resistencia y el deseo, la pulsión ética y la pasión constructiva, la articulación del sentido de la insuficiencia de lo existente y el extremo vigor de la reacción ante una intolerable ausencia de ser. Es ahí donde la potencia se forma como poder constituyente, no por buscar institucionalidad sino por construir más ser: ser ético, ser social, comunidad.

[...] El deseo de comunidad es el fantasma y el ánima del poder constituyente, deseo de una comunidad tan real como ausente, trama y motor de un movimiento cuya determinación esencial es la demanda de ser, repetida urgente sobre una ausencia. (Aunque) lo que es potente puede ser y no ser. (NEGRI, 1993).

El riesgo, la incertidumbre, la creatividad son el campo del poder constituyente; el orden, la seguridad jurídica, la homologación son el campo del poder constituido. La visión institucionalista refuerza el temor del poder constituido a la emergencia de fuerzas desconocidas que pueden alterar el orden prefigurado. 
En el poder constituyente no se trata de la emergencia de una potencia abstracta, sino de un sujeto histórico, desde el campo de los "no-contados", (RANCIERE, 1996) la militancia de comunidad en un acontecimiento (BADIOU, 1990). El imaginario constituyente se construyó desde las luchas sociales antisistémicas. El poder constituyente

[...] significa antes que nada establecer una continua relación entre poder constituyente y revolución, una relación íntima y circular: así que allí donde hay poder constituyente hay revolución. (NEGRI, 1993).

La nueva hegemonía parte de darle un sentido diferente a la revolución, cortar su deseo de comunidad para centrarla en el deseo del individuo hecho ciudadano, la ruptura entre la liberación económica y la liberación política.

Lo que aquí se desvanece es la esencia misma del poder constituyente, su eficacia histórica, que se presenta siempre y solamente como acción colectiva. Queda de él una pálida imagen liberal, allí donde por el contrario la potencia del poder constituyente es siempre y solamente democrática. El poder constituyente es confiado a la ética, hurtado por lo tanto a la política; confiado al individuo, hurtado a la colectividad. El poder constituyente es neutralizado en el individualismo. (NEGRI, 1993).

La libertad y la igualdad pasan por el tamiz de la competencia y la meritocracia, con lo cual terminan metamorfoseándose en una nueva forma de exclusión y jerarquía.

Se trata de un salto adelante en la modernización capitalista: el viejo límite territorial del poder constituyente, efectivo en la vigencia de los Estados nacionales, se transforma en el novísimo límite temporal de un Estado nacionaltrasnacionalizado, en donde el tiempo del capital ordena las formas de la vida: el bío-poder (FOUCALT, 2005), controla ya no sólo el tiempo de la producción material, sino el tiempo de la reproducción de la vida.

El signo principal actual de este giro está en el discurso neoconstitucionalista de la vigencia permanente de los derechos constitucionales, más allá del vacío de la norma jurídica, y en el discurso neoinstitucionalista, que terminan abriendo la puerta a la discrecionalidad del poder, a formas autoritarias de poder. De esta forma se abre paso una estructura política que junta discursos garantistas y participaciones institucionalizadas con prácticas de control concentrado desde el Estado: el paso a democracias disciplinarias (DAVALOS, 2010).
La derrota, cooptación y transformismo de los movimientos sociales no significan anulación, sino el paso a otras formas de disputa de la hegemonía, aunque allí la propia visión sobre la hegemonía se modifica: ya no se trata de la hegemonía en la diversidad, que termina imponiendo un límite, un centro; sino de la hegemonía de la diversidad, (ANTEZAMA, 1991) en donde el sentido y, sobre todo, el deseo de la comunidad terminan por descentrar el poder y colocarlo en el campo de la vida; la posibilidad de fundar tanto un nuevo sentido como un nuevo deseo del tiempo y del espacio, quizás no en contra de la modernidad, sino de su alternativa, en un diálogo entre los aportes, sometidos a la crítica, de Occidente y la originalidad de nuestra América.

\section{SIGNOS ANTISISTÉMICOS}

En estos tiempos de integración de las ciencias, quizás debemos buscar auxilio en otros campos teóricos para tratar de entender la complejidad estructural de nuestras realidades actuales.

En la física, las reglas que gobiernan la existencia de las partículas virtuales se hallan establecidas por el principio de incertidumbre y la ley de la conservación de la materia y la energía. Los procesos de producción de partículas proceden por simetrías rotas, a partir de simetrías originarias. Por lo que es posible descubrir cierta estética en las teorías sobre el orden del universo (FERRIS, 2012).

La historia de la sociedad moderna pasa por ciclos y discontinuidades, períodos de hegemonía que revelan a la sociedad civil simetrías estéticas que pronto son rotas por la descarga de energía, para transformarse en nuevos períodos de disputa. Desacuerdos arriba y abajo que abren períodos de transición complejos, hacia nuevas hegemonías con un sentido diferente de simetría, aceptado por el conjunto de la sociedad.

Las crisis toman cada vez formas más complejas. El sistema capitalista es altamente flexible y encuentra salidas cíclicas, pero en cada ciclo se presentan salidas cada vez más complejas, simetrías rotas más profundas. La complejidad actual está en las formas extremas de los ciclos y en la aceleración de los tiempos, con posibilidades de salidas antisistémicas. Por ello, las salidas parciales terminan siendo absorbidas por la fuerza gravitatoria del capital.

Cuando reflexionamos sobre los gobiernos progresistas de nuestra América nos sorprenden dos extremos: la alta capacidad para absorber la energía social y generar un consenso pasivo amplio con débiles oposiciones; pero al mismo tiempo la alta incapacidad para cumplir el discurso del cambio estructural y la reproducción ampliada de formas anteriores de acumulación del capital, en una especie de retorno al capital rentista y a las acumulaciones originarias internas y externas. 
Ante el riesgo de crisis estructurales, el sistema capitalista muestra su flexibilidad extrema en las formas más avanzadas de respuesta ante las demandas constituyentes de las fuerzas subalternas, para retenerlas en el borde del juego sistémico. En este sentido, los gobiernos progresistas se presentan como las formas más avanzadas de reforma dentro de los límites sistémicos. No se trata de gobiernos de coyuntura, sino de gobiernos de período, que asumen la tarea de la modernización de la economía y el Estado ante las nuevas condiciones de la globalización capitalista.

"En una república burguesa la Asamblea Constituyente representa la forma superior de democracia." (LENIN, 1973). El momento constituyente recoge la forma más avanzada de la democracia capitalista y se mueve en una paradoja: la proclama de principios rebasan los juegos del sistema, para volver en la parte orgánica a sus propias reglas. Y luego el ajuste hegemónico no ha avanzado en la radicalización de los procesos, sino más bien en derechizaciones y funcionalizaciones al poder real.

La agonía de los regímenes progresistas está en mirar la tierra prometida al otro lado de la ribera, al otro lado del abismo. Y esa agonía se presenta nuevamente desde la acción de las fuerzas subalternas, en nuevos procesos de subjetivación.

\section{CONCLUSION}

El sistema capitalista produce sus propios sepultureros, pero no en la forma deductiva de las lecturas sobre el proletariado; sino en la formas complejas de un proceso que combina subalternidadantagonismo-autonomía, en una combinación de condiciones objetivas y subjetivaciones. (MODONEZI, 2010).

El signo del tiempo actual es la apertura de nuevos procesos de subjetivación social con autonomía de los gobiernos progresistas. Después de un período de bonanza y de crecimiento, se inicia un lento proceso de recomposición de fuerzas sociales y políticas con propuestas alternativas.

Tomemos tres signos de estos procesos: la resistencia de los pueblos originarios en el TIPNIS en Bolivia; las luchas antiextractivistas en Ecuador y, en particular, el proyecto del Yasuní-ITT; y las movilizaciones por el pasaje libre en Brasil. Las resistencias ya no se realizan contra las políticas neoliberales, sino que ahora enfrentan el modelo postneoliberal.

Estas resistencias muestran el enfrentamiento entre dos visiones de la modernidad. Surgen en el cruce de dos procesos: la afectación de las condiciones y las posibilidades de vida, y la afectación al espacio y al modo de vida.

Las luchas del TIPNIS enfrentan el modelo etapista del régimen, que busca legitimar el extractivismo con el combate a la pobreza:
[...] en una primera etapa ¿acaso no es posible utilizar los recursos que brinda la actividad primaria exportadora controlada por el Estado para generar los excedentes que permitan satisfacer condiciones mínimas de vida de los bolivianos, y garantizar una educación intercultural y científica que garantice una masa crítica intelectual capaz de asumir y conducir los emergentes procesos de industrialización y de economía del conocimiento. (OSPINA, 2013).

Es sorprendente la unificación de los discursos de los gobiernos progresistas en este aspecto. El nuevo Plan Nacional del Buen Vivir (PNBV) del Gobierno de Alianza País proclama la estrategia de superar el extractivismo a través del extractivismo, para contar con los fondos necesarios para pasar a la sociedad del bioconocimiento.

En el PNBV se produce un viraje, la justificación de modelo rentista, ya no desde la lógica neoliberal de las ventajas comparativas, sino desde dos perspectivas complementarias: la vinculación del extractivismo con [...] "el rescate de la soberanía nacional, la redistribución del ingreso y la justicia social" (BENJAMIN, 2011) y el paso a la sociedad del bioconocimiento: ya no se trata únicamente del rentismo tradicional, asentado en la renta de la tierra y de los recursos naturales, sino de un neorentismo, vinculado a la nueva renta tecnológica del conocimiento.

La planificación, señala el PNBV, es ante todo el sentido del tiempo, [...] el objetivo principal de un análisis prospectivo es enfocarse en el estudio del pasado y del presente para avizorar posibles futuros."

Para AP, el punto de ruptura está en el enfrentamiento al neoliberalismo, luego llega la plenitud de un tiempo continuo, la revolución avanza, entramos en el tiempo del progreso, un horizonte de largo plazo, el 2030, hacia un nuevo modo de acumulación, distribución y redistribución. Se abre un proceso gradual de transformación de la matriz productiva, la transición de una estructura económica primario-productora a una economía generadora de alto valor agregado, mediante la constante creación del conocimiento y la innovación social y tecnológica, el paso a una estructura productiva basada en el conocimiento tecnológico.

El gran salto está en la transición de una economía de los recurso finitos - es decir, de la producción y exportación de recurso naturales hacia la apropiación científica, económica e industrial de esos recursos, para alcanzar la economía de los recursos infinitos, basada en el fortalecimiento de las capacidades y los conocimientos de la fuente más valiosa que tenemos: la población de nuestro país. El gran salto empieza por racionalizar el extractivismo.

El centro del cambio de la matriz productiva está en el impulso de los proyectos energéticos, 
junto a dos sectores estratégicos recién llegados (OSPINA, 2013): industrializar la actividad minera como eje de la transformación de la matriz (Objetivo 11) y el proyecto Yachay, la ciudad del conocimiento (Objetivo 4). Un rentismo con rostro humano y justificación social.

Hay dos fundamentos estratégicos para este viraje: la fractura entre fuerzas productivas y relaciones de producción, que desemboca en una salida centrada en la modernización tecnológica; y la visión de un tiempo continuo de progreso en etapas: como proclama el PNBV, salir del extractivismo a través del extractivismo, en la duplicación de la política de la siembra del petróleo en el período de la Dictadura de Rodríguez Lara. Una réplica de la oferta religiosa: ahora podemos aceptar el valle de lágrimas de la minería y el extractivismo, para mañana contar con la recompensa del paraíso.

El sentido profundo para el paso hacia la hegemonía 2, el sentido común en el conjunto de la sociedad, es el restablecimiento de la visión occidental-moderna del tiempo como progreso: "La idea del progreso del género humano en la historia es inseparable de la idea de su avance recorriendo un tiempo homogéneo y vacío." (BENJAMIN,2011).

Pero ya no se trata del objetivo del progreso. Vuelve el dilema de las luchas revolucionarias en América Latina, a partir de su originalidad: la superposición de las luchas antiimperialistas por la liberación nacional, con las luchas anticapitalistas por el socialismo, y las luchas civilizatorias por el comunismo.

Las movilizaciones por el pasaje libre en Brasil no se tratan únicamente de un reclamo económico, sino de la lucha por el derecho a la ciudad, por una forma de vida digna que no ha podido ser ofertada por los gobiernos del PT, a pesar de los éxitos en la economía y en el combate a la pobreza. La subjetivación de los jóvenes movilizados, una especie de semi-proletariado, pone en juego la forma de vida, ya no sólo el modo de producción.

\section{REFERÊNCIAS}

AKYÜZ, Yılmaz. Downturn in Commodity Prices, South Views, [S. I.], n. 96, 19 December 2013. Disponible en: <www.southcentre.int.>. Acceso en: 1 nov. 2013. ANTEZANA, Luis. Dos conceptos en la obra de René Zavaleta Mercado: formación abigarrada y democracia como autodeterminación. Maryland: Latin American Studies Center, Universidad de Maryland, 1991. PDF.

ANTUNES, Ricardo. Sindicalismo de clase versus Sindicalismo negociador de Estado en el Brasil de la era (pos)Lula. Herramienta, Buenos Aires, año 15, n. 47, jul. 2011.

BADIOU, Alain. ¿Se puede pensar la política? Buenos Aires: Ediciones Nueva Visión, 1990.
BEJAMIN, Walter. Tesis de filosofía de la historia. In: SÁNCHEZ, José; PIEDRAS, Pedro. A propósito de Walter Benjamin: nueva traducción y guía de lectura de las Tesis de filosofía de la historia. Revista de Filosofía, [S. I.], n. 2, n. 2 feb. 2011.

BERTERRETCHE, Juan Luis. El enclave sojero de Sudamérica. [S. I.: s. n.], 2013. Disponible en: <http://www.argenpress.info/2013/09/el-enclavesojero-de-sudamerica.html>. Acceso en: 1 oct. 2013.

CARCAMO, Rodrigo. CEPAL advierte posible fin de ciclo de precios altos de "commodities". In: JORNADA MONETARIA, 7., Bolívia. Éxitos y Desafíos para América Latina en Medio de la Crisis. Bolívia: BCB, 2013. Disponible en: <http://www.eldiario.net/ noticias/2013/2013_07/nt130726/economia.php?n=5\&cepal-advierte-posible-fin-del-ciclo-de-precios-altos-decommodities>. Acceso en: 1 nov. 2013.

COMISIÓN ECONÓMICA PARA AMÉRICA LATINA. América Latina debe ponerse dramáticamente al día en políticas industriales. América Economía, Santiago de Chile, 2013. Disponible en:<http://www.americaeconomia. com/node/103317>. Acceso en: 1 nov. 2013.

DÁVALOS, Pablo. La democracia disciplinaria: el proyecto posneoliberal para América Latina. Quito, Ecuador: CODEU, 2010.

ECHEVERRÍA, Bolívar, 2008, El ethos barroco y los indios. Revista de Filosofía Sophia, Quito-Ecuador, n. 2, 2008. Não paginado. Disponible en:<http:// es.scribd.com/doc/22551904/Bolivar-Echeverria-ElEthos-Barroco>. Acceso en: 1 nov. 2013.

FERRIS, Timthy. La aventura del espacio: de Aristóteles a la Teoría de los cuantos - una historia sin fin. Crítica, Barcelona, p. 394, 2012.

FOUCAULT, Michel. Historia de la sexualidad volumen I: la voluntad de saber. Madrid: Siglo XXI, 2005.

HARVEY, David. El "nuevo imperialismo: acumulación por desposesión. Socialist Register, [S. I.], 2004. Disponible en: <http://socialistregister.com/index. php/srv/article/view/14997\#.UrRGpNLuLTo>. Acceso en: 1 nov. 2013.

LANDER, Edgardo. Tensiones/contradicciones en torno al extractivismo en los procesos de cambio: Bolivia, Venezuela, Ecuador. In: et al. Promesas en su laberinto: cambios y continuidades en los gobiernos progresistas de América Latina. Reimp. Quito, Ecuador: IEE/CEDLA/CIM, 2013. p. 13 y 14.

LENIN, V. I. Obras escogidas: tesis sobre la Asamblea Constituyente - tomo IV 1917 - enero de 1918. Buenos Aires: Editorial Cartago, 1973. p. 571. 
MODONESI, Massimo. El final de la revolución pasiva en Brasil. [s. I.: s. n.], 23 junio 2013. Disponible en: <http://www.rebelion.org/noticia. php?id=170116\&titular=el-final-de-la-revoluci\%F3npasiva-en-brasil->. Acceso en: 1 nov. 2013.

MODONESI, Massimo. Subalternidad, antagonismo y autonomía: marxismo y subjetivación política. Buenos Aires: CLACSO, 2010.

NEGRI, Toni. El poder constituyente: ensayo sobre las alternativas de la modernidad. Madrid: Editorial Libertaria Prodhufi, 1993. Disponible en: <http://es.scribd.com/doc/77632054/Anthroposn\%C2\%BA-144-mayo-1993-Antonio-Negri-Unateoria-del-poder-constituyentehttp://es.scribd. com/doc/77632054/Anthropos-n\%C2\%BA-144mayo-1993-Antonio-Negri-Una-teoria-del-poderconstituyente>. Acceso en: 1 mar. 2013.

OSPINA, Pablo. Ecuador: el nuevo período de gobierno y el cambio de la matriz productiva. Informe de coyuntura, [S. I.], Quito, Ecuador, jul. 2013.

RANCIERE, Jacques. El desacuerdo: política y filosofía. Buenos Aires: Ediciones Nueva Visión, 1996

SALTOS, Napoleón. Estado, régimen y poder, Ecuador y Venezuela 1998-2013. Quito: ISP, Editorial Amaranta, 2013a.

SALTOS, Napoleón. Movimientos sociales y poder contrahegemónico en América Latina. In: JORNADAS INTERNACIONALES DE CIENCIAS SOCIALES Y POLÍTICAS, 6., 2013, San Luis. Anais... San Luis: PPGPP/UFMA, 2013b.

SANTOS, Boaventura de Souza. Democratizar la democracia: los caminos de la democracia participativa. México: Fondo de Cultura Económica, 2004.

ZAVALETA, René. Formas de operar el Estado en América Latina: bonapartismo, populismo, autoritarismo. In: IBARGÜEN Maya; DE LOS RÍOS, Norma (Coord.). Ensayos, testimonio y re-visiones. Buenos Aires: Miño y Dávila Editores, 2006.

\section{NOTAS}

1 Tomado de http://www.eljoropo.com/site/crudovenezolano-baja-31-centavos-y-cierra-la-semanaen-9709/, Crudo Venezolano baja 31 centavos y cierra en $\$ 97,09,21$ diciembre 2013.

2 Las citas están tomadas de SENPLADES, Plan Nacional del Buen Vivir 2013-2017, PDF.

\section{Napoleon Saltos Galarza}

Licenciado en Ciencias de la Educación y Sicología Egresado en Filosofía, Pontificia Universidad Católica del Ecuador, Quito.

Profesor Titular de la Universidad Central del Ecuador E-mail:wnsaltosg@yahoo.es

\section{Universidade Central do Equador - UCE \\ Cuidadela Universitaria, \\ Quito, Equador}

